\section{An econometric analysis of modernized cereal production in reducing multidimensional poverty in Uganda, 1975-2014}

Modernized cereal production

\author{
Emong Herbert Robert
}

Faculty of Graduate Studies for Statistical Researches, Department of Applied Statistics and Econometrics, Cairo University, Cairo, Egypt
Received 24 April 2020 Revised 16 July 2020 9 May 2021 Accepted 9 May 2021

\begin{abstract}
Purpose - This study aims to develop an econometric analysis of how modern agriculture can be a fundamental instrument for reducing the levels of multidimensional poverty in Uganda. It demonstrates the importance of agriculture in reducing inequalities amongst the poor while focusing on the relationship between increasing productions from modern agricultural practices and the poverty level across the country.

Design/methodology/approach - The study explores Box-Jenkins approach to cereal production data with the use of econometric analysis as the main tool to determine the implications of modern agricultural practices in Uganda. Most poor people around the world are in marginalized rural environments, and agriculture provides for their livelihoods. This makes agricultural development crucial for reducing multidimensional poverty on a large scale and needs development within agriculture to be enhanced. Education, health and standard of living are the three dimensions considered from the weighted indicators, amounting to $30 \%$, to be categorized poor in the three dimensions.

Findings - Modernization of agriculture is an ultimate solution to multidimensional poverty reduction in Uganda through employment generation and the effects of food prices. Shreds of evidence support the theories that agricultural incomes together with the actual wages increase with a general rise in the rural nonagricultural economy. Results depict a close correlation between national income and GDP per capita which is a very significant indication that more application of agricultural technology would lead to a sub sequential improvement of livelihoods engaged in agricultural practices.

Originality/value - Agriculture remains a vital sector that employs a greater portion of the population in Uganda's economy. Major roles have been played by the sector in the economy including employment opportunities, rural household incomes, food supplies and a reduction in poverty from a multidimensional front. Exploring the behavior of poverty level using modern agriculture as an indicator and its relationship with the poverty level arising from improved agricultural practices could provide a meaningful display of variation in poverty across the regions at the country level.
\end{abstract}

Keywords Agriculture, GDP, Growth, Household, Livelihood, Modernization, Multidimensional poverty, Uganda

Paper type Research paper

(C) Emong Herbert Robert. Published in Review of Economics and Political Science. Published by Emerald Publishing Limited. This article is published under the Creative Commons Attribution (CC BY 4.0) licence. Anyone may reproduce, distribute, translate and create derivative works of this article (for both commercial and non-commercial purposes), subject to full attribution to the original publication and authors. The full terms of this licence maybe seen at http://creativecommons.org/ licences/by/4.0/legalcode

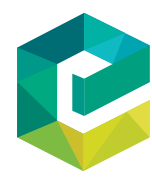

Review of Economics and Political Science Emerald Publishing Limited e-ISSN: 2631-3561 DOI 10.1108/REPS-04-2020-0051 


\section{Introduction}

Uganda's dependence on agriculture and her aspirations for modern agriculture descended in the time since the 1960s. For many years, the main goal has been to commercialize the sector Flygare (2006) labeled as being subsistent based. This objective is referred by Nabudere (1997) as the politics of modernization in Africa. Major research studies have emphasized how Uganda can benefit from the modernization of agriculture by acknowledging its importance to the economy, and a lots of suggestions have been made for the whole concept of modernization practiced as universal and desirable to be revisited. The starting point is the actual experiences of the poor who are quite vulnerable to these strategies (Wiggins and Leturque, 2010).

Most of the food productions in Uganda come from the local subsistence agricultural system and are the major revenue earnings to the population. The transformation in the agricultural sector should therefore be a modern one which enhances higher farm productivity due to the applications of modern agricultural technologies. This will improve incomes and employment levels across the country. These prospects follow the national government's driven agriculture modernization strategy in conjunction with external agencies that are working toward determining ways in which food production and incomes can be sustained (Flygare, 2006).

Part 1of this paper therefore provides an introduction of modern agriculture in Uganda. The literature review including the agricultural potentials and the roles played are described in Section 2. Multidimensional poverty in Uganda, approaches, and some common measures of poverty in Section 3. Section 4 provides the main results and discussions using the Minitab and SPSS programs. The agricultural share to gross domestic product (GDP) and conclusion are given in Sections 5 and 6, respectively.

\section{Literature review}

Uganda's agricultural zones determine the natural agricultural production potentials, and most of these zones receive bimodal rainfall that allows double harvest while applying improved agricultural norms. This has further caused differences in income generation and the impacts realized from modern agriculture to poverty across all the regions in Uganda due to differences within yields, investments in infrastructure and greater access to local and national markets as shown on Figure 1 (i and ii) (Ruecker, 2003).

More than three - quarters of the country has a regional precipitation pattern that promotes double harvests in those zones. These agricultural areas have favorable lengths of growing periods and demographic growth arises from both parturition and relocation of people. Market access is better within these areas due to improved infrastructural developments, and the real acreage yield varies by districts coinciding with these agricultural potential zones. Areas with favorable conditions such as good climates, better infrastructural developments and better yields of the major crops tend to have better access to markets with these crops-fetching pleasant prices than other regions (USAID, 2007).

Almost all agricultural productions take place on small plots of lands with about $40 \%$ of the plots mixed with lots of other food crops. The sector however registered a positive growth rate of $2.6 \%$ in 2009 although this is below the targeted rate of $6 \%$ per annum set by the African Union. Other than Uganda, the rich and poor countries also have small farms with smaller average sizes of farm plots. Most of their sectors are dominated by small plots operated by family members who own most of the key productive resources (Uganda Bureau of Statistics (UBOS) and Macro International Inc, 2007).

Asian countries have smaller farms than Sub-Saharan Africa countries averagely. Central America and Europe also do not have bigger farmlands, yet this has not prevented 


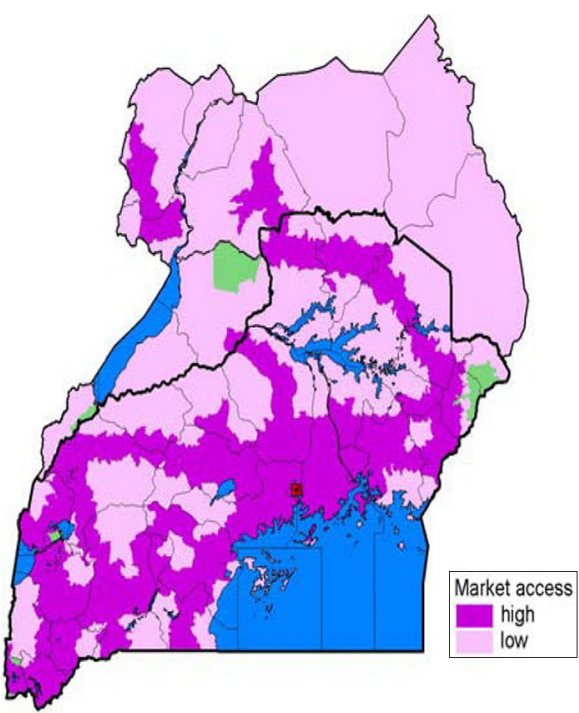

(a)

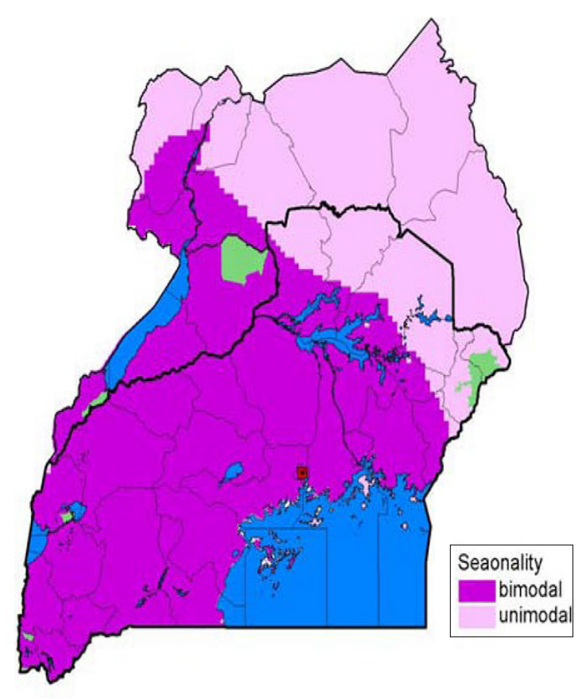

(b)

Source: Ruecker et al. (2003)

the vulnerable poor population from this region to generate significant revenues to enhance growth. Eastwood (2010) emphasized on a reverse correlation between the agricultural farm sizes and realized revenues per acre of land. He particularly pointed more returns realized from smaller farms per acre which is three times bigger than the larger farms at a national level.

Land availability greatly determines the size of farmlands, yet many regions of Uganda are faced with a growing population yet their farmlands are limited. Uganda's land sized and the acreages are only relative to Malawi unlike neighboring countries including Kenya, Tanzania, Democratic Republic of Congo and Sudan enjoy 2-3 times higher rates. Fuglie (2009) therefore recommended smallholder agricultural practices as the most viable strategy (Table 1).

\begin{tabular}{lccccc}
\hline Selected Countries & 1971-1980 & 1981-1990 & 1991-1900 & 2001-2008 & 2009-2016 \\
\hline Ethiopia & 3.04 & 2.39 & 1.76 & 1.35 & 0.16 \\
Kenya & 4.11 & 2.83 & 2.05 & 1.62 & 0.12 \\
Malawi & 1.74 & 1.22 & 0.90 & 0.72 & 0.23 \\
Sudan & 13.31 & 9.79 & 7.59 & 6.19 & 0.28 \\
Tanzania & 5.44 & 3.99 & 2.92 & 2.30 & 0.26 \\
Uganda & 1.77 & 1.30 & 0.92 & 0.70 & 0.19 \\
Zambia & 14.87 & 10.76 & 8.02 & 6.39 & 0.24 \\
Sun-Sahara Africa & 6.97 & 5.23 & 3.90 & 3.14 & 0.22 \\
World & 3.16 & 2.65 & 2.27 & 2.02 & 0.02
\end{tabular}

Source: World Bank (2019)

Modernized cereal production

Figure 1.

Domains that determine natural agricultural potential and market access in Uganda

Table 1.

Land area in selected countries, hectare (ha) per capita 


\section{REPS}

Larger farms are unquestionably more profiting and commercializing and yet Uganda's agricultural sector in general faces challenges of limited availability of farmlands, poor infrastructural developments, lack of capital, low production and productivity, poor marketing system, human resource constraints and over-reliance on unpredictable weather conditions. The economy needs major transformation aimed at liberalizing agriculture markets, removing key obstacles to agricultural trade amongst others and may therefore be an ultimate tool for reviving the economy. These transformations are projected to enhance food security in rural areas, generate more revenues for the poor households and hence reducing multidimensional poverty across Uganda (World Bank, 2019).

\subsection{Role of agriculture}

Agriculture is a vital sector in Uganda's economy playing major roles including employment opportunities, rural household incomes, food supplies and multidimensional poverty reduction. However, its share has been significantly declining over time accounting for $56 \%$ of GDP in the early 1980s, but a recent study found the share to have fallen to $15.4 \%$. This declining share has not only affected livelihoods and food security in Uganda but also raised major concerns in other sub-Saharan African countries that highly depend on the importation of agricultural products from Uganda. There is therefore need to increase agricultural productivity through modern agricultural practices (World Bank, 2012) (Table 2).

Most of the service sectors have single-digit growth performance and low impacts on the GDP. The manufacturing sector's contribution to GDP has picked up over the years with market liberalization and enabling policies although with very little yearly contributions. Liberalization of markets has allowed for the unrestrained capital flow of investments by foreign firms the encouraged an enormous return of profits to the mother countries from these sectors and therefore not reflected into the GDP hence more focus on areas that benefit the national economy.

Major progress in Uganda's agricultural sector is highly dependent on how the country takes advantage of science and modern systems. Urban and subsistence agriculture has made a significant contribution to the well-being of the poor urban dwellers. It supplements their incomes, creates employment opportunities and contributes to the sustainability of food baskets.

\section{Multidimensional poverty in Uganda}

Poverty is quite a difficult phenomenon and its concept is more than signifying only a lack of material resources. It also includes a lack of other human needs such as freedom, access to

Table 2.

Share of primary growth sectors in GDP and growth performance in Uganda

\begin{tabular}{lrrrrr}
\hline & \multicolumn{5}{c}{ \% share in GDP } \\
Growth Sectors & 2014 & 2015 & 2016 & 2017 & 2018 \\
\hline Agriculture & 20.2 & 20.1 & 21.7 & 22.7 & 23.0 \\
Forestry & 1.8 & 2.2 & 3.8 & 5.1 & 4.2 \\
Manufacturing & 18.2 & 16.7 & 15.5 & 16.0 & 15.1 \\
Hotels and restaurants & 2.4 & 2.6 & 3.2 & 2.9 & 3.0 \\
Mining & 1.2 & 1.2 & 1.3 & 1.5 & 1.1 \\
Post and telecom & 1.9 & 2.6 & 1.8 & 2.1 & 2.1 \\
Construction & 5.5 & 5.8 & 5.7 & 5.8 & 6.2
\end{tabular}

Source: The Republic of Uganda (2013) 
clean drinking water, access to power and inadequate opportunities and choices. Poverty cannot be explained or defined by a single measure. A significant number of authors and researchers have asserted the need of having poverty defined from a multidimensional perspective and oppose basing mainly only on income. A lot must then be done to embrace the various dimensions of deprivation, real-world definition and some practical measurement of poverty. Attempts have been made by integrating various attributes into an index using some arbitrary function so that the poverty line and the practical measures are then considered.

Alkire and Santos (2010) elaborated on how poverty maps for Uganda and other developing countries widely vary. The discrepancies are alleged to arise from agricultural zones and agro-climatic conditions, infrastructural access to markets, water bodies and political factors. Uganda's endeavors to reduce income poverty is determined from education, health and standard of living. This multidimensional approach sheds light on a variety of deprivations measured using different indicators and the methodology is proposed by Foster. A family is therefore considered multidimensionally poor if the weighted indicators from the areas they are deprived of are about $30 \%$ of their summation. Alkire and Santos (2010) used the income poverty approach in their recent studies and considered the sum of the weighted indicator to be $20 \%$ particularly depending on relative poverty.

Appleton (2001) acknowledged the shape reduction in poverty in Uganda attributable to the expansion of the middle class although a large percentage of insecure people persisted throughout the period as elaborated in Table.4. Growth in the middle class is a basis for transformation due to the prospects of investments from their savings. A large population are however either poor or insecure non-poor and can still fall to poverty.

Oxford Initiative and Human Development report (2010) emphasized the multiple deprivations facing people in the three dimensions. The approach depicts different patterns of poverty than income poverty or poverty line derived from consumption which Uganda adapted. Uganda draws its poverty assessment from two poverty lines including the daily expenses on food and non-nutritive items coupled with the poverty lines adopted by the World Bank Report of 2019 is at US\$1.90 per day and US\$690 per capita per annum.

Sen (1997) elaborated on how human lives are reduced during different courses of action and recommended considering compound views of poverty and dimensions in which people are deprived of to shed more light on a variety of these deprivations measured using the ten indicators below.

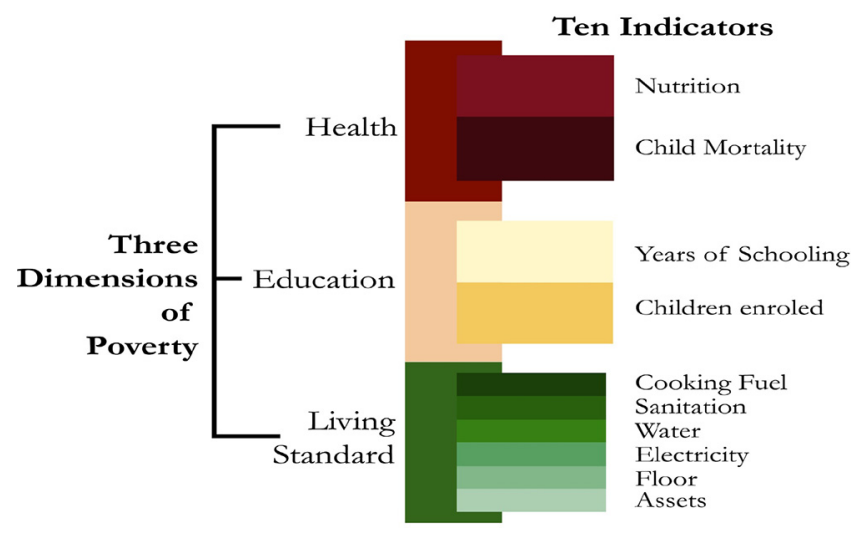


The multidimensional poverty index (MPI) therefore determines people's poverty level based on the sum of weighted deprivations from indicators organized under three dimensions that are equally weighted, and about a third of these indicators identify a person as multidimensionally poor.

Poverty maps for Uganda show a lot of variation across all dimensions including income distributions in both urban and rural regions. These differences emanate from heterogeneous geographic and agro-climatic conditions, infrastructural access to markets amongst others (Kates and Dasgupta, 2007).

Ugandans attaining middle-class status have increased by over 10 million in years from 7.8 million in 2005/2006 to 19.5 million in 2016/2017. Over 6 million Ugandans attained middle-class status during 2012/2013-2016/2017 alone although many may also exit poverty and failed to attain middle-class status. The number of individuals above the national poverty line (insecure non-poor) in 2016/2017 was about 1.5 times higher than in 2005/2006 (10.9 million). This group is classified as non-poor and highly vulnerable with occurrences of shocks such as a drought able to push them into poverty. This explains how important the country needs to embark on modern agricultural practices to facilitate their initiatives to eradicate poverty within its boundaries (The Republic of Uganda, 2013) (Table 3).

\section{Main results and discussion}

This section explores the behavior of poverty level using modern agriculture as an indicator, and interest is focused on increasing productions of major crops in Uganda and its relationship with the poverty level arising from improved agricultural practices. A necessary characteristic of these variables is that they could be aggregated meaningfully and display variation across the regions at the country level. This analysis will assess how the modernization of agriculture has improved the total production of these major crops, mainly cereals, and crop productions hence earning more revenues to the farmers engaged in agriculture.

\subsection{Methodology and data}

Statistical analysis in this section is based on the secondary data from the UBOS and Uganda Census Agriculture for the period from 1975 to 2014, a period when Uganda is considered to have registered an average growth rate of about $6.4 \%$ per annum. This represents about $50 \%$ of the original data, yet according to UBOS, this portion of the data is fairly representative and provide the same findings as to the full data. Applications of the Box-Jenkins approach is explored to cereal production data during the sampling process to determine any systematic patterns in cereal production.

\section{Table 3.}

Current trends in Uganda poverty status at a national level

\begin{tabular}{lcccccrc}
\hline & & \multicolumn{2}{c}{ Poor } & \multicolumn{2}{c}{ Insecure non-poor } & \multicolumn{2}{c}{ Middle class } \\
Years & Population (Millions) & Millions & $(\%)$ & Millions & $(\%)$ & Millions & $(\%)$ \\
\hline $2005 / 2006$ & 27.2 & 8.4 & 31.1 & 10.9 & 40.2 & 7.8 & 28.7 \\
$2009 / 2010$ & 30.7 & 7.5 & 24.5 & 13.2 & 42.9 & 10.0 & 32.6 \\
$2012 / 2013$ & 34.1 & 6.7 & 19.7 & 14.7 & 43.3 & 12.6 & 37.0 \\
$2016 / 2017$ & 41.2 & 8.0 & 19.4 & 18.6 & 45.2 & 19.5 & 47.4
\end{tabular}

Source: UNHS, 2016/2017 
Table 4 below presents the descriptive statistics for some selected variables of agriculture for the comparison of their means.

The minimum productions for each output were above 35 tonnes per hectare with maximums of above 100 tonnes per hectare each indicating more benefits as a result of using better agricultural practices. Cereal productions are seen to have the lowest relative variations within the major agricultural outputs as a result of more improved and mechanized agricultural practices in Uganda compared to crop, food and livestock productions. This has arisen because of the better revenues the rural population generates from cereals to the application of modern agricultural practices hence improving the welfare of more livelihoods.

Trend analysis on Figure 2 further enhanced the spotting of any systematic patterns over time for cereal productions to the application of modern agricultural practices which should be reflected on the poverty levels of the country.

Cereal production is having an increasing linear trend and seasonal fluctuations because of the increasing mean and pattern of fluctuations. In particular, the seasonal variation is on a yearly. It can also be noticed there are some outliers between the years 1981 to 1987, and

\begin{tabular}{lccrrr}
\hline Statistical Measures & Cereal production & Crop production & Food production & Livestock production \\
\hline Minimum & 1041.9 & 48.38 & 45.08 & 36.44 \\
Maximum & 2143.3 & 111.30 & 113.58 & 127.34 & 67.98 \\
Mean & 1543.9 & 81.34 & 77.06 & 58.58 & Statistical measures \\
Median & 1526.0 & 77.48 & 70.59 & 881.11 & Table 4. \\
Variance & 71528.9 & 365.93 & 468.01 & 29.89 & for some selected \\
Standard Deviation & 267.4 & 19.13 & 21.63 & 0.82 & variables of \\
Coefficient of Variation & 17.32 & 23.52 & 0.36 & 0.80 & agriculture in \\
Skewness & 0.64 & 0.02 & 1.27 & & Uganda \\
Kurtosis & 0.22 & 1.28 & & & \\
\hline
\end{tabular}

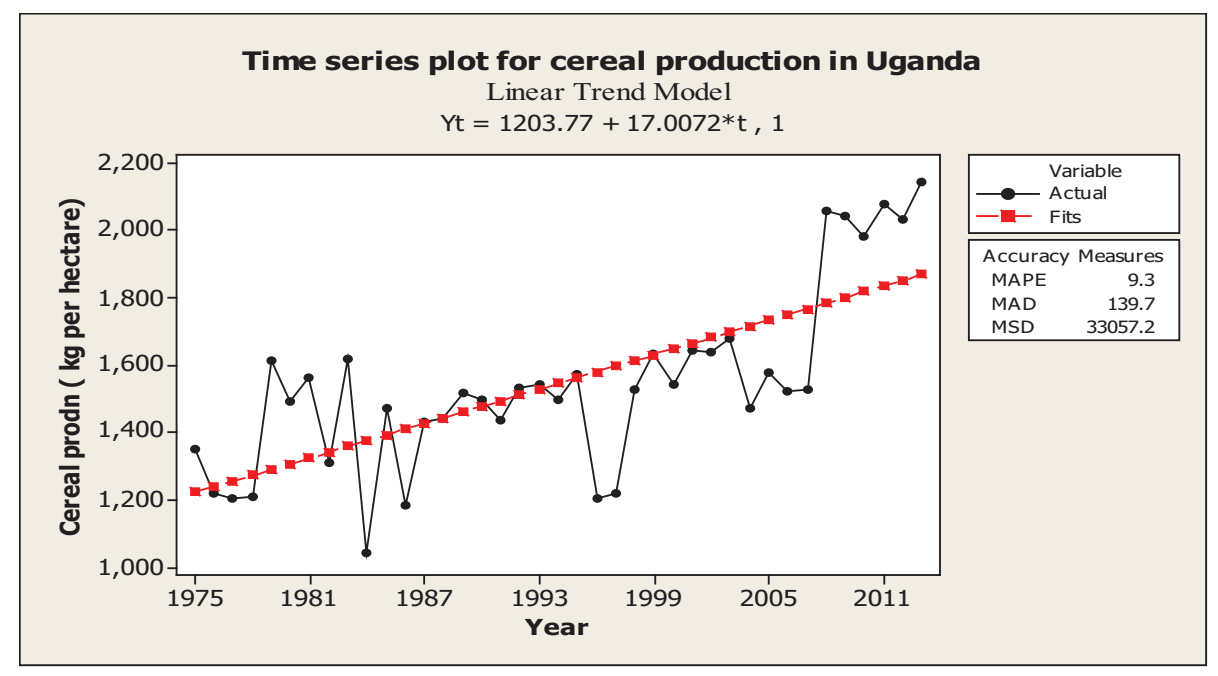

Modernized cereal production

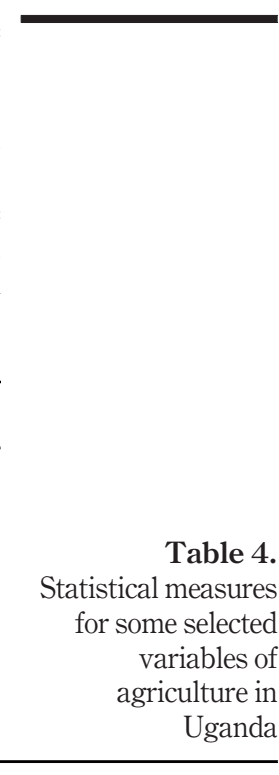


after 2005, this is direct evidence of high agricultural productivity in the early 1980s with growing contributions to the GDP from the agricultural sector; this is a matter for poverty reduction. An increase in the cereal productions increases the export market share participation, and this in return improves the general welfare of the local farmers who are engaged in modern agricultural activities, a positive trend on multidimensional poverty within the regions of Uganda.

General agricultural productivity is seen to have remarkable performance after 2005 because the government and its development partners intensified their efforts toward modern agriculture as a tool for reducing multidimensional poverty in Uganda. The trend spotted in cereal productivities was therefore removed by taking the first difference as shown in Figure 3.

Stationarity is obtained during the first difference though with the presence of some outliers, indicating major productions in some years and regions due to the application of modern agricultural technologies within the four regions and therefore a difference in the impacts realized from reduced poverty, especially the western side of Uganda which has favorable conditions ranging from improved infrastructural developments to better access to local markets.

The accuracy measures above are explored to assess determining the best performing model. Based on all these criteria, the ARIMA $(1,1,2)$ model is seen to provide better results than other models in Table 5.

Figure 3.

First difference plot for cereal production

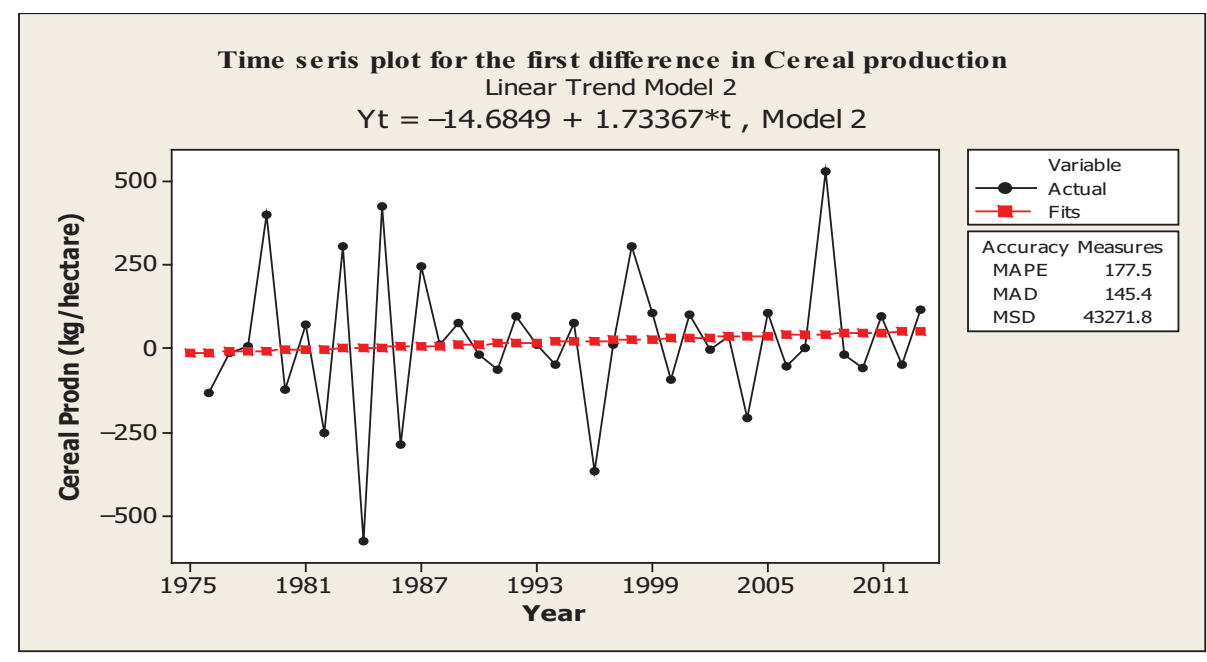

Table 5.

The computed RMSE, MAE, MAPE, and R-Squared values for Model 1

\begin{tabular}{llccc}
\hline Model & RMSE & MAE & MAPE & $R$-Squared \\
\hline ARIMA (1,1,0) & 184.616 & 122.303 & 8.149 & 0.606 \\
ARIMA (1,1,1) & 193.41 & 127.484 & 8.661 & 0.567 \\
ARIMA (1,1,2) & 145.6 & 85.639 & 6.035 & 0.778 \\
\hline
\end{tabular}


The average annual cereal yields or productions can then be forecasted by ARIMA $(1,1,2)$ confirmed by the final estimate of parameters (Table 6).

The residual plots in Figure 4 above confirm that all the parameters are significantly different from zero, the $p$-values of both the moving average and autoregressive models are significantly smaller than 0.05 . Considering randomness on the residuals, the residual plots displayed depict a white noise model that is confirmed by Ljung-Box results. This is an indication that the fitted model seems appropriate.

The Minitab output in Figure 5 above confirms that an ARIMA $(1,1,2)$ is the appropriate model for this series. We do acknowledge that ACF dies positively very slowly with increases in the lags, whereas PACF cuts off after Lag 1. The Ljung-Box test shown confirms the variations and the non-stationarity realized due to a boost in cereal productions from modern agriculture. The residuals of the sample ACF further depict an approximate correlation of the residuals and therefore a presence of a model in the process. There are high autocorrelations at low lags although decaying gradually with a rise in lags of trended series. The detrending approach of taking first or second differences is explored to transform this non-stationarity in cereal production timeseries data (Figure 6).

Differencing the series once cause the ACF to change and cut off after the first lag, whereas PACF remained unchanged after differencing once which is an indication that the ARIMA $(1,1,2)$ model is appropriate for the series and the parameters should be significant.

\begin{tabular}{lccccr}
\hline Type & Coef & SE Coef & T & P & \\
\hline AR 1 & 0.7353 & 0.1359 & 5.41 & $<0.0001$ & Table 6. \\
MA 1 & 1.3817 & 0.0805 & 17.17 & $<0.0001$ & Parameters estimates \\
MA 2 & -0.4100 & 0.1218 & -3.37 & 0.002 & for Model 1 \\
Constant & 4.981 & 1.440 & 3.46 & $<0.0001$ & \\
\hline
\end{tabular}

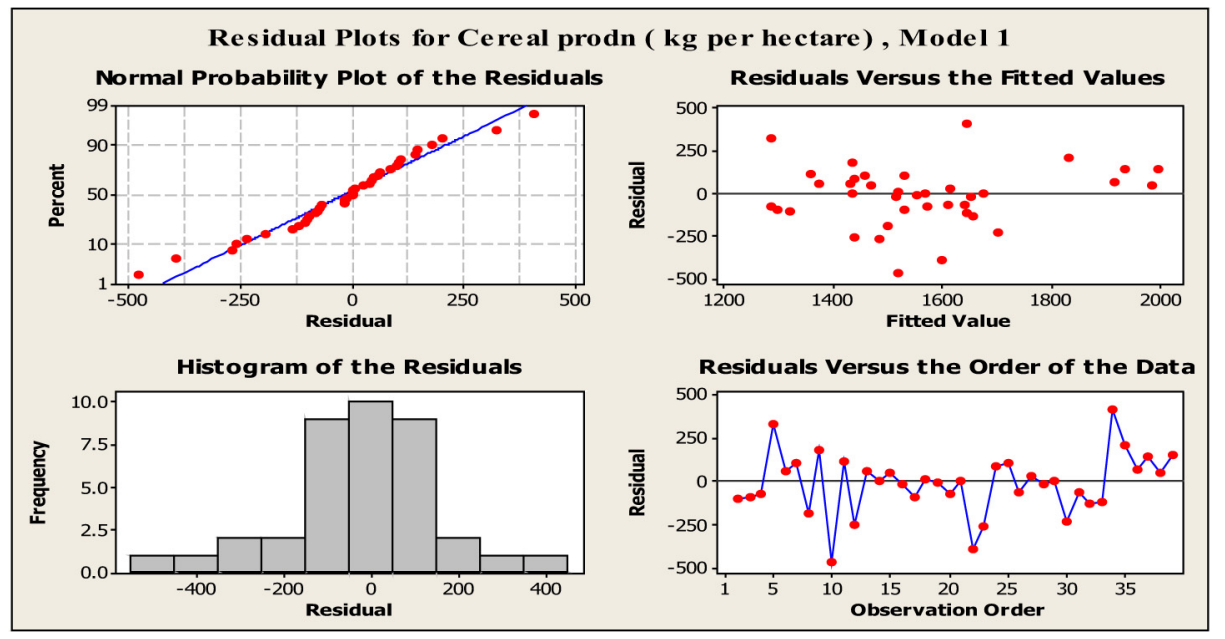

Figure 4.

Four-in-one residual plots for cereal productions 


\section{REPS}

Crop production is the second major agricultural output in Uganda with a steady increase in its productivities since the late 1980s with the applications of modern agricultural practices. The major crop has always been coffee that earned Uganda major foreign currencies from its exports and boosting the efforts to reduce or eradicate multidimensional poverty in Uganda. The increasing linear trend shown in Figure 7 indicates some yearly seasonal fluctuations of coffee prices witnessed in the international market.

\section{Agricultural share to gross domestic product}

Time series data is explored as a tool to examine the agricultural contribution to the GDP of the Ugandan economy with its potential roles to multidimensional poverty reductions. Regression analysis (OLS) is performed to get desired results and from the analysis, and beneficial statistical information can guide reaching appropriate decisions. To test this hypothesis empirically, the role of agriculture on the GDP and its correlation to poverty, the model can be specified as follows (Tables 7 and 8):

$$
\mathrm{Y}=\beta_{0}+\beta_{1} \text { Agri }+\beta_{2} \text { Ind }+\beta_{3} \text { Trade }+\beta_{4} \text { Manuf }+\mathrm{C}
$$

Where,

$\mathrm{Y}=\mathrm{GDP}$ (billion dollars);

Agri $=$ Agricultural;

Ind = Industry;

Trade $=$ Trade;

Figure 5.

ACF and PACF plots on cereal production for Model 1

\section{Figure 6.}

Differenced $\mathrm{ACF}$ and PACF Plots on cereal production for Model 2
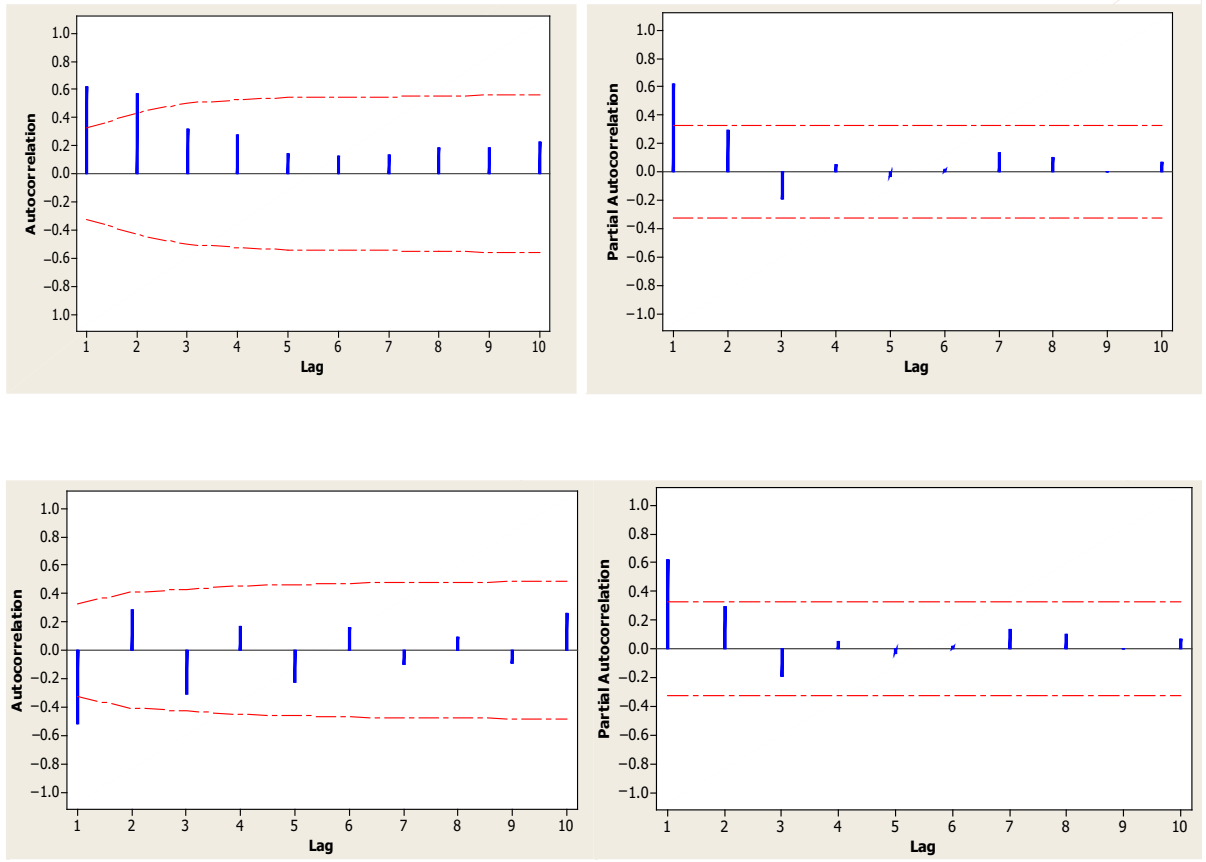


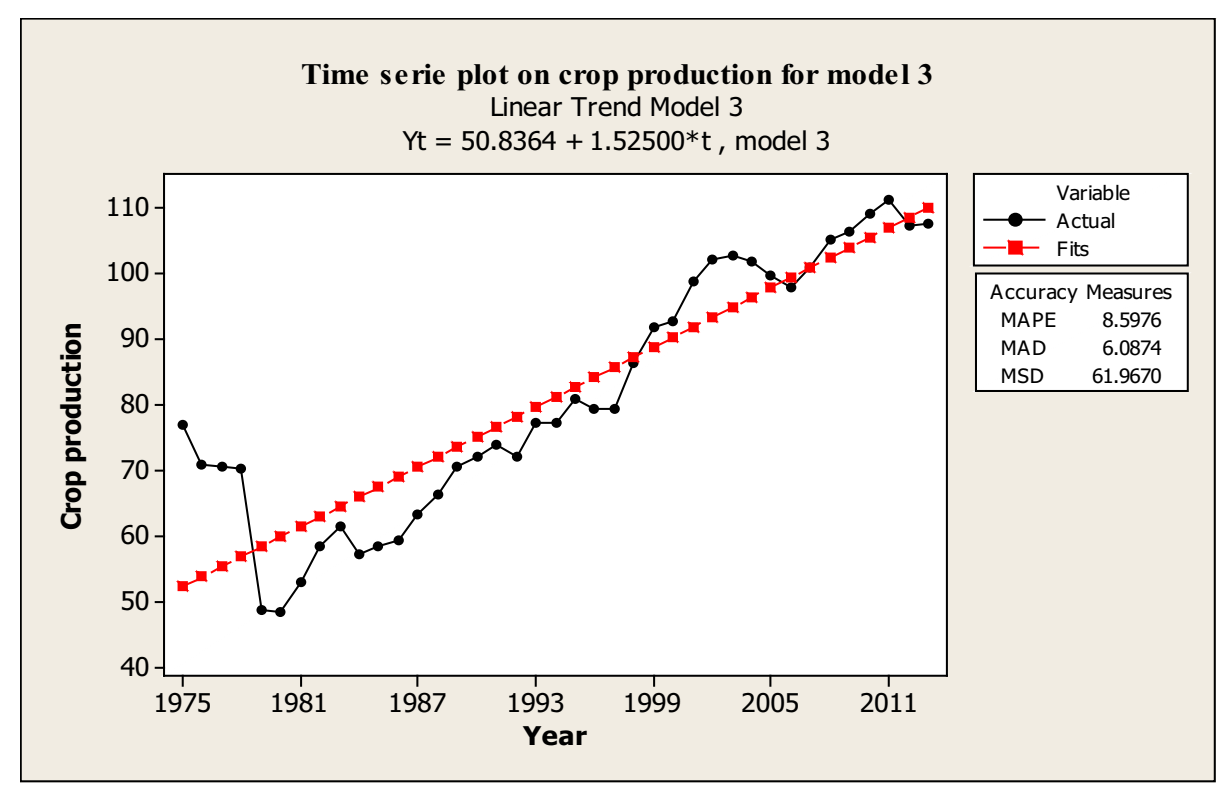

\begin{tabular}{lrcrrr}
\hline Predictor & Coef & SE Coef & T & P & VIF \\
\hline Constant & 155.0 & 310.4 & 0.50 & 0.621 & \\
Agriculture & -0.4165 & 0.3531 & -1.18 & 0.246 & 18.3 \\
Trade & 0.7237 & 0.2247 & 3.22 & 0.003 & 3.3 \\
Industry & -1.6445 & 0.7945 & -2.07 & 0.046 & 15.2 \\
Manufacturing & 5.1378 & 0.9982 & 5.15 & $<0.0001$ & 2.4 \\
\hline & & & & \\
\hline Source of Variation & DF & SS & MS & F & P \\
\hline Regression & 4 & 257322994 & 64330749 & 30.57 & $<0.0001$ \\
Residual Error & 34 & 71554847 & 2104554 & & \\
Total & 38 & 328877841 & & &
\end{tabular}

Modernized cereal

production

Figure 7.

Trend analysis for crop production $(2004-2006=100)$
Table 7.

GDP and Agriculture, trade, industry, and manufacturing for

Model 4

Manuf $=$ Manufacturing; and
MSE $=1450.71 \boldsymbol{R}-\mathbf{S q}=78.2 \% \boldsymbol{R}-\mathbf{S q}(\mathbf{a d j})=75.7 \%$.

The value of $R$-square is a statistical measure that constitutes the proportion of variance from the dependent variables being explained in the model. This indicates that approximately $78 \%$ variation in the GDP of the Uganda economy is described by Agriculture, Industry, Trade and Manufacturing. The significance of F. value depicts the models to be a good fit. As per expectation, the GDP of Uganda is positive but affected by declining shares from the agriculture sector which play an important role. 
REPS

Table 9.

Correlations of variables in Model 4
The occurrence of correlation is possible in almost all-time series data. Table 9 does not show any existence perfect correlation between all variables under consideration. Gujarati (1988) and Judge et al. (1988) stressed correlation varying from -0.97 to 0.78 in the model that is not very high. However, 0.80 is considered to be the critical threshold for the serious problem of correlation. Industry, trade and manufacturing all have positive correlations except agriculture because of a shape decline in its contributions to the GDP of Uganda. This is supporting how importantly the country needs to embark on modern agricultural practices to facilitate their initiatives to eradicate poverty within its boundaries. Recent concerns have been at institutional and organizational levels among the many different agencies and bodies in Uganda that are mandated with the agriculture modernization program. The role of agriculture to Uganda's GDP is unquestionable both directly and indirectly by providing livelihoods to over $80 \%$ of the population, government expenditures in different sectors begin to pick up gradually due to revenues realized from agricultural practices hence an improvement to multidimensional poverty across Uganda.

There are increasing linear trend and seasonal fluctuations because of the increasing means and pattern of peaks and valleys illustrated in Figure 8. National income and GDP per capita have almost the same peaks and valleys because of the close correlation between

\begin{tabular}{lccccr}
\hline Variable Name & GDP & AGRI & IND & TRADE & MANUF \\
\hline GDP & 1 & -0.589 & 0.558 & 0.642 & 0.775 \\
AGRI & - & 1 & -0.968 & -0.695 & -0.707 \\
IND & - & - & 1 & 0.640 & 0.735 \\
TRADE & - & - & - & 1 & 0.534 \\
MANUF & - & - & - & - & 1 \\
\hline
\end{tabular}

Figure 8.

GDP and per capita income plot

\section{Time series plot for National Income and GDP of Uganda}
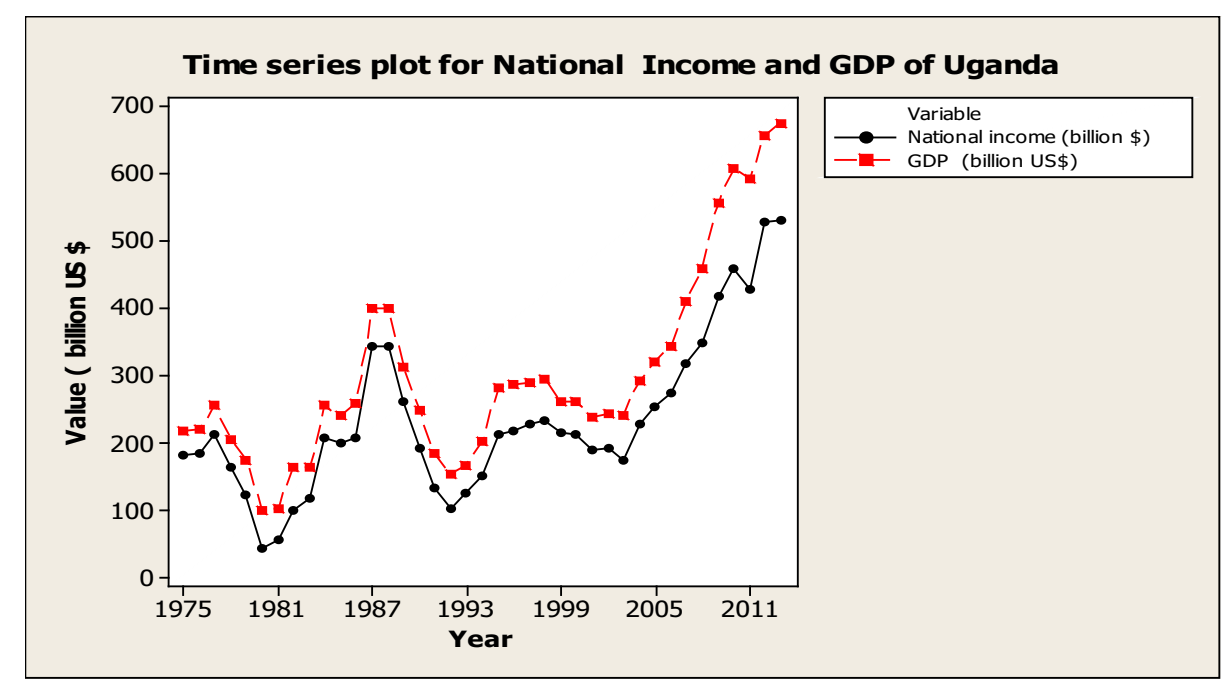

Source: Computed by the researcher based on UBOS,1975-2014 
the two variables. A very significant indication that more application of agricultural technology would lead to a sub sequential improvement of livelihoods engaged in agricultural practices. This is of no doubt a positive impact on government endeavors in reducing multidimensional poverty within Uganda.

\section{Conclusions}

Uganda has greater prospects for agricultural development. They are better now than several years ago than Asia and Latin American countries during their agricultural revolutionary period. Much empirical evidence in Uganda is for the government to motivate and advocate more on modern agricultural productivity and one can conclude as follows.

Modernization of agriculture will be an ultimate solution to multidimensional poverty reduction in Uganda directly by increasing real household incomes, indirectly through employment generation and food price effects. Evidence supports the theories that farm incomes grow with a proportionate growth in the countryside non-farm economy. Real household incomes will also be positively impacted by a decrease in the proportion of the population exiting poverty. Sustaining major progress in poverty reduction from more modernized agriculture should therefore evaluate and assess the relationship of basic public services to general well-being. Greater focus must also be directed towards the poor and most importantly the vulnerable during the process of transformation.

\section{References}

Alkire, S. and Santos, M. (2010), "Acute multidimensional poverty: a new index for developing countries", Human Development Research Paper 11, UNDP-HDRO, New York, NY.

Appleton, S. (2001), "Changes in poverty and inequality', chapter 4", in: Collier, P. and Reinnikka, R. (Eds), Uganda's Recovery: The Role of Farms, Firms and Government, World Bank, Washington, DC, pp. 83-121.

Eastwood, R., Lipton, M. and Newell, A. (2010), "Farm size”, in: Pingali, P. and Evenson, E. (Eds), Handbook of Agricultural Economics, Elsevier, North Holland.

Flygare, S. (2006), The Cooperative Challenge: Farmer Cooperation and the Politics of Agricultural Modernization in 21st Century Uganda, Uppsala Studies in Economic History, Uppsala.

Fuglie, K. (2009), “Agricultural productivity in Sub-Saharan Africa”, USDA, Economic Research Service. Paper presented at the Cornell University Symposium on the Food and Financial Crises and their Impact on the Achievement of the Millennium Development Goals, New York, NY.

Gujarati, D.N. (1988), Basic Econometrics, McGraw-Hill, New York.

Judge, G., Hill, R., Griffiths, W., Lutkepohl, H. and Lee, T. (1988), Introduction to Theory and Practice of Economtrics, 2nd ed., Wiley, New York, NW.

Kates, R.W. and Dasgupta, P. (2007), "African poverty: a grand challenge for sustainability science", Proceedings of the National Academy of Sciences, Vol. 104 No. 43, pp. 16747-16750.

Nabudere, D.W. (1997), "Beyond modernization and development, or why the poor reject development", Geografiska Annaler. Series B, Human Geography, Vol. 79.

Republic of Uganda (2013), Uganda National Panel Survey 2011/2012, UBOS Publication.

Ruecker, G., Park, S., Ssali, H. and Pender, J. (2003), "Strategic targeting of development policies to a complex region: a GIS-based stratification applied to Uganda", ZEF Discussion Paper 69, Center for Development Research, University of Bonn, Bonn.
Modernized cereal production 
Uganda Bureau of Statistics (UBOS) and Macro International Inc (2007), Uganda Demographic and Health Survey 2006, UBOS and Macro International, Calverton, MD.

USAID (2007), "Uganda: Formative Evaluation of the Agricultural Productivity Enhancement Program (APEP), Final Report”. Washington, DC.

Wiggins, S. and Leturque, H. (2010), Helping Africa to Feed Itself: Promoting Agriculture to Reduce Poverty and Hunger, World Bank, London, ODI.

World Bank (2012), 'Uganda: Promoting Inclusive Growth, Synthesis Report. Washington, DC.

World Bank (2019), World Development Indicators, World Bank, Washington, DC.

\section{Further reading}

World Bank (2009). World Development Indicators, World Bank, Washington, DC.

\section{Corresponding author}

Emong Herbert Robert can be contacted at: herbertist64@yahoo.co.uk

For instructions on how to order reprints of this article, please visit our website: 